\title{
A ARQUITETURA NUNCA MAIS SERÁ A MESMA. CONSIDERAÇÕES SOBRE GÉNERO E ESPAÇO(S)
}

\section{ARCHITECTURE WILL NEVER BE THE SAME AGAIN. THOUGHTS ABOUT GENDER AND SPACE(S)}

v. 7, n. 2 [11]

ago/dez (2015)

Artigo
Lia Pereira Saraiva Gil Antunes

Portugal

lia_a@hotmail.com

\section{Resumo}

A arquitetura tem apoiado o seu reconhecimento na vida dos "grandes mestres", como "faróis históricos" capazes de legitimar a quase totalidade de um discurso disciplinar - têm-se investigado quais as consequências desta visão unilateral da história e quais as alternativas possíveis. Procura-se explorar as formas como as mulheres vivenciam e ocupam o espaço, enquanto utilizadoras, e expor a problemática da construção da cidade e da arquitetura como uma prática maioritariamente masculina. Pensa-se também uma tentativa de reformulação da arquitetura, enquanto instituição, e da sua história, que visa incluir as perspetivas das arquitetas e desvendar o mainstream da disciplina.

\section{Palavras-chave}

Arquitetura, Género, Espaço, Mulher

\begin{abstract}
Architecture has supported its recognition in the life of the "great masters", as "historic lighthouses" able to legitimize almost of an entire disciplinary discourse. Some aspects of the theory of architecture and many feminist theorists have investigated the consequences of this sided view of history and what the possible alternatives. It seeks the ways women experience and occupy space, as users, and expose the problems of city building and architecture as a practice mostly male. There is an attempt to remodel the architecture as an institution and its history that seeks to include the perspectives of architects and unravel the mainstream of the discipline.
\end{abstract}

\section{Keywords}

Architecture, Gender, Space, Woman 


\section{Introdução}

Women today are exerting pressure on the architecture profession just as other entering groups, particularly the Black power movement, did in the nineteen-sixties. Architecture will never be the same again (BROWN, 2011, p.113)

A arquitetura não é apenas um abrigo ou refúgio, uma habitação ou um edifício; as questões que a envolvem têm implicações epistemológicas, ontológicas e políticas. Na complexidade das funções material, cultural e metafísica, a ideia de arquitetura que circula é mais ou menos consensual, embora abstrata e simplista, vagueando entre a racionalidade e a tecnologia por um lado, e a arte e criatividade por outro. Todavia, independentemente de todos os conceitos e adjetivos que lhe são atribuídos, é clara a perceção de que foi e permanece uma atividade masculina.

A arquitetura é uma disciplina que exige ser entendida num contexto, isto é, dentro do contexto social, político e cultural da sua produção e no contexto da sua representação, interpretação e consumo, através de diferentes abordagens académicas, instituições e grupos de interesses. Assim, seguindo as mudanças ocorridas nos debates teóricos, históricos e críticos, particularmente no que diz respeito ao feminismo, entender o espaço em relação ao género continua a pedir uma urgente contextualização e constante debate.

\section{Género e Espaço}

As mulheres têm estado envolvidas com o desenho e forma do espaço de várias maneiras, enquanto praticantes, teóricas, consumistas, historiadoras e objetos de representação. Todavia, a arquitetura tem sido dominada pelos princípios e regras masculinos e a mulher tem sido relegada ao seu papel biológico de mãe e constrangida à domesticidade, à casa e ao mundo privado; até há poucas décadas atrás, por exemplo, não Ihes era permitida a integração no mundo académico.

Procurar um vínculo entre as disciplinas de arquitetura e género (e política, dada a natureza do tema) tem-se revelado um trabalho complexo, até difícil. Além das interrogações simultâneas sobre os vários níveis em que intervêm e interatuam na construção da cidade, da casa, dos espaços e da próprias vida, descobrir as posições da mulher na arquitetura e no mundo revelam-se pertinentes para uns, demasiado radicais e fora de tempo e de contexto para os mais céticos (ou iludidos). Esta procura, esta preocupação, este desassossego, parecem surgir um pouco contracorrente na época da globalização - é provocadora para o discurso e para a teoria da arquitetura, para a história da arquitetura, para o século XXI e, sobretudo, para o contexto português.

Se por um lado, a principal preocupação é produzir ambientes sensíveis capazes de responder às necessidades do homem/mulher que habitam o espaço em questão, por outro, a arquitetura e a cidade ocidentais foram essencialmente produzidas e dirigidas ao "white middleclass men" (WHITE, 2001, p.17). Será que interessa à sociedade em geral que o ambiente construído seja produzido apenas por um grupo restritos de pessoas, referentes a um género e 
classe específicos? Por que razão é que as mulheres, as crianças e as minorias no geral, estão ausentes do processo de pensar a cidade e reinterpretar o espaço público? Porque ainda não existe esta consciência e pela primazia de outros interesses. O discurso da arquitetura ocidental está envolvido com a (penetrante) masculinidade, que é construída em oposição e pela subordinação do "feminino". As narrativas e histórias arquitetónicas, os conceitos, a linguagem e o vocabulário, as preocupações e os programas, as práticas e os processos, traduzem-se numa orientação masculinizada do mainstream da disciplina, em contraste com outras profissões. Historicamente ligada à realidade e à imaginação urbanas, a constante evolução do género oferece inúmeras possibilidades de repensar as conexões entre a subjetividade, a interpretação e o espaço urbano.

O ambiente construído como "fundo" e a arquitetura como "figura" refletem e reforçam as divisões culturais, sociais e económicas da sociedade, e são específicos num determinado tempo e espaço onde se produzem as relações de poder. Foucault afirma que "[...] space is fundamental in any form of communal life; space is fundamental to any exercise of power" (apud WHITE, 2001, p.16). Apesar da arquitetura se desenvolver atualmente no meio do sistema capitalista, com todas as suas infraestruturas políticas e económicas, os arquitetos e teóricos continuam a reclamar o status de Artista através de mitos heroicos que justifiquem as suas escolhas sobre o espaço. A verdade é que, contrariamente a este cenário, as mulheres podem ter outra abordagem ao ambiente construído e às relações que este estabelece com o sistema instituído; como refere Virginia Woolf, em A Room of One's Own,

If one is a woman one is often surprised at a sudden splitting off of consciousness [...] when from being the neutral inheritor of that civilization, she becomes, on the contrary, outsider of it, alien and critical (apud WHITE, 2001, p.17).

É importante reconhecer que tal como o espaço tem reproduzido as divisões de género pela ocupação física - as diferentes ocupações e usos por homens, mulheres e outros géneros também o espaço é produzido por questões de género através das representações. As descrições são feitas pelo uso de palavras e de imagens que estabelecem associações com as formas do corpo, curvilíneas e femininas ou fálicas e masculinas, demasiado forçadas.

Se o espaço assume questões de género e, se sim, como é que o faz, é um tema problemático. Levanta-se uma série de questões: se há produção de espaço/género esta é feita através de atos intencionais do processo de projeto de acordo com o sexo do arquiteto ou é produzida pela via interpretativa da crítica, história e teoria da arquitetura? Noutra perspetiva, esta relação entre questões de género e o ambiente construído pode ser realizada pelo uso: determinados espaços podem ser pensados de acordo com o "sexo biológico" das pessoas que os ocupam ou com as diferentes atividades que ai decorrem? 


\section{A questão multidisciplinar do discurso sobre a natureza de gênero do espaço}

As abordagens ao masculino/feminino e a sua relação com o ambiente construído fazem-se através de estudos interdisciplinares, dentro e fora da arquitetura, que procuraram a base de trabalho e inspiração nos trabalhos feministas de geografia, antropologia, história da arte, estudos culturais, psicanálise e filosofia. Estas áreas pensaram e debateram o espaço, através das representações e das metáforas espaciais, questões distintas da definição tradicional dada pela arquitetura: o modo como o espaço é encontrado, usado, ocupado e transformado pelas atividades do quotidiano. A base teórica deste discurso provém das perceções conceptuais da teoria feminista contemporânea e dos termos "falocentrismo", "feminino", "masculinidade", o "outro", a "alteridade", relacionados diretamente com o espaço. Como Mark Wigley (1992) refere, o discurso arquitetónico é paradigmaticamente "intertextual" e depende e influencia outras esferas da produção cultural. O conhecimento base da arquitetura entende o mundo através de uma moldura limitada - a racionalidade, conotada por muitos autores como masculina - assumindo que o arquiteto é um observador objetivo e o edifício uma expressão transparente dessa visão:

\footnotetext{
After examining many of the founding texts of philosophy, science and political theory and history, feminists have argued that the notion of reason as developed from the seventeenth century onwards is not gender neutral. On contrary, it works in tandem with white bourgeois heterosexual masculinities [...] Masculinist rationality is a form of knowledge which assumes a knower who believes he can separate himself from his body, emotions, values, past and so on, so that he and his thought are autonomous, contextfree and objective... the assumptions of an objectivity untainted by any particular social position allows this kind of rationality to claim itself as universal (BOYS, 1996, p.34).
}

Os estudos urbanos produziram importantes implicações sociais e epistemológicas que reforçaram o questionamento do papel e da função do espaço público, tantas vezes transformado em palco de uma visão etnocêntrica, sexista e limitada da realidade social. Em oposição a este cenário monocultural e reducionista na conceção do espaço urbano, as perspetivas pósmodernas exaltam uma outra leitura, de compromisso social e crítico das várias ciências que se debruçam sobre a análise da cidade e do urbano.

\section{Arquitetura, Pós-Modernismo e Feminismo}

Muitos teóricos têm argumentado que o pós-modernismo representa uma reação contra a homogeneização da cultura de massa da sociedade capitalista. Uma das manifestações desta reação é o renovado interesse nas especificidades sociais e históricas, o particular e o "descentrado" na cultura ocidental - o local, o regional, a diversidade étnica e o sexo feminino. Consequentemente, a trajetória da modernidade/pós-modernidade teve diferentes implicações no percurso das mulheres e dos homens - diversos trabalhos apontam para a exclusão das mulheres da modernidade, e a sua posterior recuperação dentro da pós-modernidade. Os adjetivos e as metáforas usados para descrever o diferente variam entre híbrido, heterogéneo, 
descontínuo, anti totalizante, ou incerto, e acompanham a nova imagem do labirinto pósmoderno, fragmentado e múltiplo, sem o centro convencional.

Dentro do campo da arquitetura, a deslegitimação do modernismo tem sido interpretada e reinterpretada com diversas atitudes e surge frequentemente associada a uma crise de representação - dos processos económicos, políticos, culturais e de projeto. Contrariamente ao pensamento racional e purista moderno, o pós-modernismo produz novas abordagens à arquitetura através de uma ampla diversidade de discursos que moldaram um novo terreno para a disciplina e a profissão, que foram (e são) significativamente modificados por esta atitude pósmoderna. Aqui foi importante a reconceptualização da arquitetura como linguagem; todavia, o "falar sobre arquitetura" continua a desenvolver-se no centro, no mainstream, com regras definidas que não permitem deslizes nem a criação de espaços de liberdade e de respiração. As alterações no quadro conceptual, a multiplicidade e diversidade de discursos caracterizam a importância do pós-modernismo, pensado não como um estilo singular mas através da perceção de integrar teorias pluralistas. Neste sentido, Jorge Figueira nota que

\begin{abstract}
A abordagem da história da arquitetura moderna por Mark Wigley usando a temática da moda, ou por Beatriz Colomina, numa perspetiva feminista, traduzem esse alargamento. $\mathrm{Na}$ teoria é o pós-modernismo que reenquadra o feminismo, o pós-colonialismo, e suporta os estudos culturais (FIGUEIRA, 2011, p.11).
\end{abstract}

Durante a primeira onda feminista, nos anos 60 e 70, surgiu uma expressão artística baseada em grande parte na rejeição de qualquer coisa considerada tradicional e, portanto, do domínio patriarcal. Os impulsos visuais deram lugar a novas experiências formais e à arte performativa. Nos anos 70, a maior parte do trabalho feminista especificamente focado na arquitetura abrangeu um pequeno número de abordagens alternativas - procuraram as protagonistas esquecidas na história da arquitetura e tentaram compensá-las através da história e teoria feministas. Na viragem para a década de 80 explora-se o potencial de uma "arquitetura feminista" que inclui e se desenvolve através da "estética feminista" (alterando a aparência e a interpretação dos edifícios), numa procura por alternativas aos modos convencionais de praticar arquitetura (a forma como os edifícios são produzidos). Mas é nos anos 90 que surgem diversas antologias de textos, que resultam frequentemente de conferências e exposições, onde o debate sobre a mulher na arquitetura - como utilizadora ou arquiteta - se começa a fazer de forma mais profunda e por uma ampla diversidade de áreas do conhecimento: "Space is today understood differently by the feminist theorists who are increasingly concerned with issues of mobility, 'nomadism', 'positioning' and 'situatedness'" (PETRESCU, 2007, p.xviii). Debate-se a domesticidade, a casa, a arquitetura e a cidade contemporâneas, através da metodologia e da linguagem feministas e pelo discurso heterogéneo; garante-se, assim, a continuidade da inquietação na admissão da mulher nesta área. Atualmente, o debate é variado e o trabalho feminista mais recente sugere que

[...] radical practice should not only concentrate on solving problems in a practical way but also critique architecture as a form of representation consisting of images and 
writing. Such a shift, which involves thinking about architectural practice as text as well as building, may be characterized as postmodern and opens up possibilities for many different approaches to the feminist practice of architecture (RENDELL, 2000, p.233).

\section{Os usos do "feminino" e os problemas da categorização e dos estereótipos no discurso sobre o espaço}

$\mathrm{Na}$ introdução ao livro Feminine Sexuality (1985), Jacqueline Rose relembra a forma como a generalização das categorias de "macho" e "fêmea" é prejudicial para a compreensão da sexualidade; quando estas classificações pretendem representar o absoluto e a divisão entre género, perdem as entidades complementares e as identidades próprias de cada indivíduo. A recente teoria de género rejeitou as definições biológicas de sexo como essencialistas, por não oferecerem possibilidade à emancipação da mulher a favor da construção social e cultural de género. Apesar de os termos "macho" e "fêmea" terem sido alterados para "masculino" e "feminino", não alteraram os assuntos estratégicos e epistemológicos. Conforme a teoria feminista se foi tornando mais sofisticada e multivocal, o "feminino" também foi sendo explorado como uma marca do sistema e da inscrição patriarcal do "outro".

o "feminino" é encriptado no espaço e, consequentemente, dominado e subjugado, numa imagem que aparece como um segredo escondido, como um código que necessita de ser decifrado. Através desta inscrição no espaço, o género torna-se um objeto de desconhecimento, ou não reconhecimento, e escapa a uma análise. A feminização do espaço está implícita no modo como as metáforas os conceitos carregam e reproduzem os termos sexuais. Assim, torna-se quase naturalmente permitido que o espaço receba as "características femininas" de passividade, inatividade e ausência de discurso.

Na modernidade, o "feminino" foi alegorizado pela figura da prostituta, como mercadoria ou objeto útil, tornando-se um símbolo inevitável de uma nova história de "ver e ser visto", de "representável ou irrepresentável". Através das alegorias, o "feminino" passa a depender de imagens, visões e cenários, que ligam o visível e o invisível, a vida e o sonho, simbolizando o artifício e a ilusão modernista. O "feminino" capta a natureza dupla das coisas, é a fonte de angústias e a promessa de prazer. No caso do filme noir, o papel da mulher é dirigido para a ideia de femme fatale, geralmente associada aos medos dos homens em relação à sexualidade feminina: ela aparece como uma figura ambivalente ligada ao excesso e a algo que tem de ser evitado.

Embora a mulher contemporânea ainda seja muitas vezes excluída da disciplina, o conceito de "mulher" e de "feminino" tem lugar nos textos de arquitetura enquanto metáforas em diversos contextos. A masculinidade destes textos é frequentemente definida em termos de distância/diferença em relação à oposição/hostilidade com o "feminino". A mulher foi tomada muitas vezes como musa para o artista masculino, pela duvidosa legitimação da mitologia clássica; as formas do "feminino" foram vistas como um símbolo ou metáfora para se pensar a cidade e o edifício. Os textos ocidentais convencionais assumem que a humanidade - a 
civilização (ocidental) humana - é masculina e, por isso, a natureza resulta de uma apropriação do "feminino" e da "alteridade" como símbolo.

\section{A linguagem também é um lugar de luta ${ }^{1}$}

A apreciação e classificação do mundo físico estão dependentes das perceções sociais que se fazem em relação a este e a forma como o ser humano percebe os padrões do domínio social é aplicada aos significados dos conceitos, à classificação e à divisão em grupos - conceitos como "alta sociedade", "esferas de interesse" e "círculos políticos" vão influenciar o espaço e a perceção que se tem deste. O espaço reflete a organização social e, assim que este esteja devidamente limitado e moldado, deixa de ser um background neutro.

"We are now in an era where discourse is as important as design" (AGREST et al., 1996, p.11). Na revelação da arquitetura como um sistema de símbolos e na dissociação entre a imagem e a realidade, o discurso e a teoria arquitetónicos ganharam força mas permaneceram inscritos no mainstream (masculino). Como refere Mark Wigley,

Theory has always described itself as a kind of building [...] So thinking about the status of architectural discourse, something as apparently simple as a 'theory of architecture' becomes complicated because the concept of theory itself established with a certain concept of architecture (apud WHITE, 2001, p.78).

É inteligível que a teoria e a crítica da arquitetura tenham como principal interesse os edifícios e as intenções subjacentes a estes, como os processos de produção e a receção perante o público. No entanto, desde o declínio do modernismo que o discurso arquitetónico entrou numa fase teórica e autorreflexiva; consequentemente, os textos de arquitetura começaram a estar sob escrutínio. A teoria pós-moderna trouxe a intertextualidade como uma característica inevitável das formações do discurso e a arquitetura apresentou-se como um exemplo elucidativo onde o conceito de linguagem - com sintaxe, gramática e citações próprias - incluiu noções de espaço, de imagens e mesmo de edifícios, dando origem a textos complexos.

O texto arquitetónico tem uma materialidade e é estruturado espacialmente, operando como um lugar metafórico através do qual são exploradas narrativas criativas. Para Jennifer Bloomer em "Big Jugs" (1991), diferentes formas de escrever expressam diferentes modos de entender a arquitetura através do que é íntimo e pessoal, o que é subjetivo em vez de objetivo, o que é sensual ao invés da pura estimulação visual. Esta perspetiva da arquitetura produz estratégias textuais que são usadas tanto na interpretação desenhos e espaços como na criação de novas noções de espaço e de criatividade, permitindo ligações entre o desenho arquitetónico e a teoria e a história da disciplina.

Todavia, o discurso da arquitetura contemporânea parece enfatizar apenas o que é novo, o que é original e simplista, numa tentativa de aproximação à atitude moderna. Brenda Vale aponta para

1 "Language is also a place of struggle" (HOOKS, 2000, p.204).

(c) Urbana: Rev. Eletrônica Cent. Interdiscip. Estud. Cid. Campinas (SP)

v.7, n.2 [11]

p. $02-23$

ISSN 1982-0569 
[...] an obsession in architecture which, like art, is novel. Architecture is now appraised on what it looks like and how different this appearance is from anything that has gone before [...] All attention is now focused on the final product and very little on the process or the performance of building (VALE, 1996, p.268).

O corpo, a sexualidade e a arquitetura, como processos de projeto, começaram a ser discutidos recentemente mas mantêm-se ainda restringidos ao debate entre (poucos) grupos, como o feminista.

As analogias e metáforas sexuais são inerentes à arquitetura? Ou elas são inerentes à linguagem que usamos para escrever e falar sobre a arquitetura? A arquitetura começou a ser interpretada em termos de espaço relacional, como uma linguagem que expressa significados em diversos contextos - por exemplo, na estrutura económica e social ou segundo valores ou qualidades femininas/masculinas. A comunicação é feita por um vocabulário formal, com gramática e sintaxe próprias e, se o significado está fora da arquitetura, a projeção deste está sempre inerente tanto na criação da forma do edifício como no ato de o observar. Assim,

Language is also a place of struggle [...] The oppressed struggle in language to recover ourselves, to reconcile, to reunite, to renew. Our words are not without meaning, they are an action, a resistance (HOOKS, 2000, p.204).

\section{O lugar da mulher na cidade e as reações ao ambiente urbano}

The man-made environment which surround us reinforce conventional patriarchal definitions of women's role in society imprint those sexist messages on our daughters and sons. They have conditioned us to an environmental myopia which limits selfconcepts... which limits our visions and choices for ways of living and working... which limits us by not providing the environments we need to support our autonomy or by barring our access to them. It is time to open our eyes and see the political nature of this environmental oppression! (WEISMAN, 2000, p.1).

É de forma direta e radical que Leslie K. Weisman inicia a sua intervenção sobre o ambiente construído (e masculinizado), em gesto de manifesto. Sem dúvida, a vida das mulheres (e das minorias) foi profundamente afetada pelo uso da cidade/periferia e pelo conceito e desenho da casa - como lugar "feminino" por excelência.

O desenvolvimento das cidades e dos subúrbios é influenciado, direta e indiretamente, pelos sistemas e mecanismo de poder e controlo, dos quais as mulheres foram sucessivamente excluídas. Nesta esfera incluem-se a arquitetura e a construção, os edifícios e os espaços públicos, que respondem à prevalecente ideia (tradicional) da natureza da família, à relação casa/trabalho e ao dualismo do espaço público/espaço privado, termos que concentravam as perspetivas de vida do homem de negócios. Após a "segunda onda" feminista, ativistas e teóricas implantaram ferramentas de análise que permitiram observar o abandono e irrelevância dada às experiências, necessidades e perceções das mulheres - a investigação permitiu identificar, por um lado, que as mulheres têm interesses diferentes do homem e que habitam outros nichos 
económicos e culturais, por outro, o modo como o ambiente construído facilita, expressa, legitima e perpetua a elevação dos interesses masculinos.

Weisman continua com "A meaningful environment is necessary and essential to a meaningful existence" (WEISMAN, 2000, p.3). Ao longo da história, as mulheres participaram em diversas manifestações e agitações por melhores condições de vida nas cidades, como Reclaim the Streets e Critical Mass, onde as práticas sociais do quotidiano formaram a base filosófica e política dos movimentos. Estes grupos exigiam melhores edifícios e espaços públicos, uma nova rede de transportes e habitações de qualidade acessíveis a todos e todas, que suportassem os estilos de vida contemporâneos, que respondessem às realidades da vida e não a fantasias culturais sobre elas. No primeiro dia do ano de 1971, na cidade de Nova Iorque, juntaram-se setenta e cinco mulheres e ocuparam um edifício abandonado na 330 East Fifth Avenue:

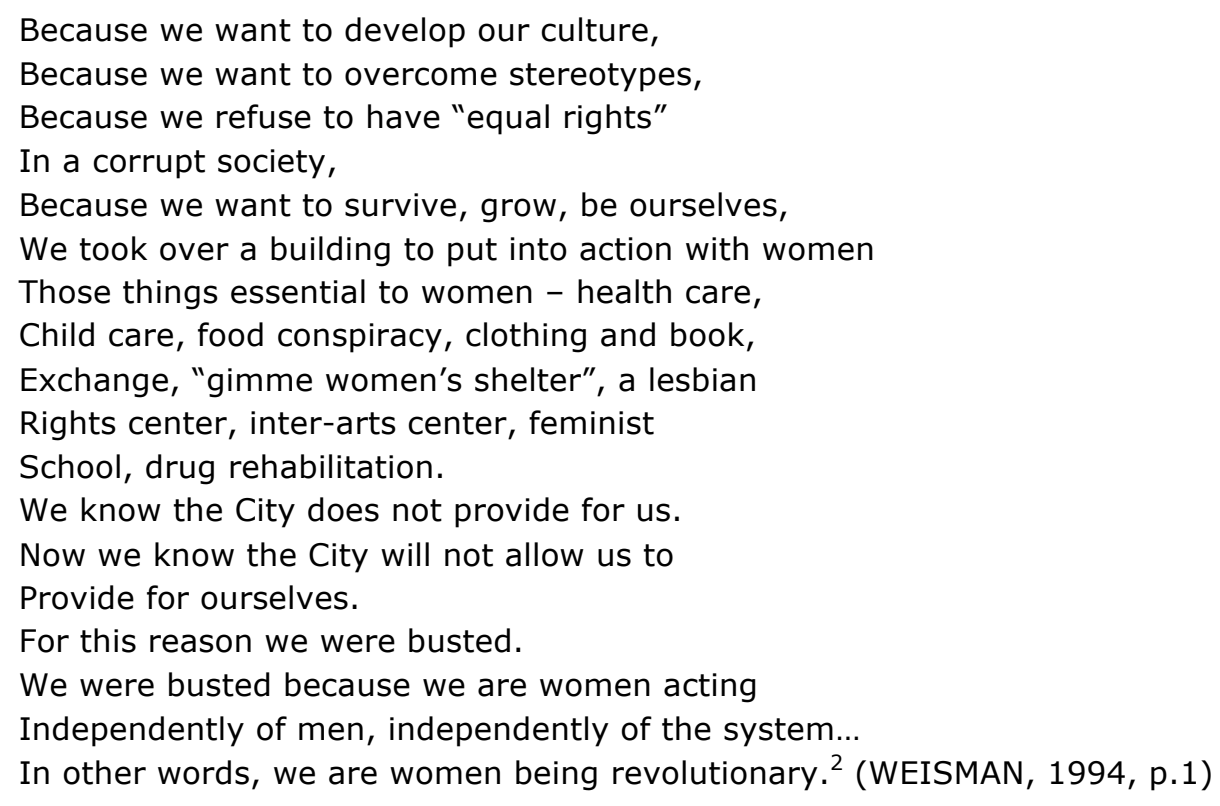

Este grupo mostrou claramente que a apropriação do espaço é um ato político, que o acesso ao espaço (sobretudo público) está relacionado com o status social e com o poder, e que a alteração do uso do espaço está inerente a uma afetação da sociedade.

Em Portugal surgiu recentemente uma espécie de guia, escrito e editado pela União de Mulheres Alternativa (UMAR) e pela equipa de investigação Faces de Eva (Universidade Nova de Lisboa) que pretende

[...] recuperar e tornar visível a voz e o protagonismo das mulheres nas suas trajetórias individuais e lutas coletivas, contribuindo para a construção da memória histórica dos feminismos, diz a UMAR. Um livro que, segundo a coautora Manuela Góis, "fazia falta porque não havia um olhar feminista sobre Lisboa e porque a história tradicional torna invisível o papel das mulheres". O objetivo destes coletivos é perpetuar a memória das feministas que passaram por Lisboa ou que, de alguma forma, a marcaram. Os roteiros

\footnotetext{
${ }^{2}$ Esta citação é referente ao Movimento Fifth Street Women's Building, publicado em The Militant (29 Janeiro 1971). Elas cantavam "Our hands / Our feet / Our minds / Our bodies / Are tools for change". (c) Urbana: Rev. Eletrônica Cent. Interdiscip. Estud. Cid. $\quad$ Campinas (SP) $\quad$ v.7, n.2 [11] $\quad$ p.02-23 ISSN 1982-0569
} 
estão sempre em atualização, porque as pessoas que querem fazer desta cidade uma cidade de justiça social e de igualdade continuam na rua. Os roteiros estão sempre incompletos, têm sempre de ser completados e redignificados (SOBRAL, 2010, s.p.).

Esta iniciativa surge pela necessidade de equilibrar a cidade no feminino e no masculino e trata-se simplesmente de repensar a cidade tendo em conta os seus múltiplos olhares e sensibilidades individuais.

A abordagem arquitetónica feita pela teoria feminista vem questionar os princípios básicos da história e da prática arquitetónicas, sugere novos objetos de estudos e propõe repensar as interpretações feitas dos mesmos. Por exemplo, em "Subjective Spaces: A Feminist Architectural History of the Burlington Arcade" (1996), Jane Rendell recorre ao período histórico compreendido entre 1811 e 1821 , momento precedente da ideologia das "esferas separadas" e da dominante configuração do espaço e do género, e às Burlington Arcades, em Londres, como espaço revelador da noção de consumo e que atuam como um arquétipo da interpenetração do espaço público com o privado. As arcadas demonstram a natureza problemática do conhecimento binário e do consumismo: o espaço foi pensado para as mulheres consumidoras mas era usado pelos homens que consumiam o corpo da mulher como exibição e como imagem.

Woman, representing both heterogeneity of matter through her body an historical negation of her gender, is in the perfect position to develop such a discourse. Woman, a discourse of heterogeneity, represents the negative in the homogeneity of the community (AGREST, 2000, p. 367).

Consequentemente, o papel das mulheres na transformação da cidade permanece fora do discurso cultural da arquitetura e do urbanismo e são conotadas, frequentemente, como agentes passivos do ambiente construído. Recentemente, têm surgido alguns trabalhos que estabelecem uma conexão crítica entre o poder e a espacialidade, focados na participação das populações marginalizadas nas alterações das cidades contemporâneas. As consequências sociais das ideologias repressivas do planeamento urbano foram apropriadas pela análise feminista, que explorou a influência das mulheres e de minorias no espaço público. Susana Torres, em "Claiming the Public Space: The Mothers of Plaza de Mayo" (2000), retrata o grupo de mulheres que, nos anos 70, ocuparam a principal praça de Buenos Aires (Argentina), a Plaza de Mayo, numa atuação contra a violência e o desaparecimento de pessoas durante a brutal ditadura militar (1976-1983). A redefinição desta praça pelas Madres de la Plaza de Mayo sugere que o domínio público existe mais pelas ações sociais que ai ocorrem do que pelos edifícios, fachadas e espaços que o compõem; a arquitetura revela-se cúmplice do poder ao criar sistemas simbólicos de representação, geralmente, através do poder das hierarquias. Estas mulheres expuseram o corpo à violência através da presença simbólica na forma de uma marcha silenciosa em volta da Pirâmide de Mayo, no centro da praça, em resposta à ordem policial que exigia a "circulação", provando que a ação coletiva consegue fazer (re)nascer o espaço público e alterar os seus significados.

A historiadora Dolores Hayden tem vindo a identificar certas características do ambiente produzido pelo homem, como as cidades insensíveis à diversidade do habitar, as ruas pouco (c) Urbana: Rev. Eletrônica Cent. Interdiscip. Estud. Cid. $\quad$ Campinas (SP) $\quad$ v.7, n.2 [11] $\quad$ p.02-23 $\quad$ ISSN 1982-0569 
hospitaleiras ou o simbolismo sexista da publicidade. Propõe então a substituição por melhores transportes públicos, por espaços públicos acessíveis à coletividade ou por uma rede mais apropriada de creches e lares de idosos. Defende a eliminação da segregação residencial por classe, etnia, ou idade, e um novo paradigma de casa, que não se molde pelos padrões tradicionais em torno da cozinha, das atividades ditas femininas e do casamento, e de bairro, com serviços adicionais que apoiem o espaço privado e os pais que trabalham. Neste sentido, ao colocar a questão "What would a non-sexist city be like?" (1980), Hayden pretende provocar sobretudo os arquitetos e urbanistas para que reconheçam os novos tipos de família como constituintes de novas abordagens de projeto, rejeitando, por exemplo, que o lugar da mulher ainda é a casa. A reabilitação e a preservação de edifícios são enfatizadas em detrimento de novas construções - sobretudo na Europa, alguns projetos foram desenvolvidos neste sentido, como o caso Steilshoop Project (Hamburgo, Alemanha) ou Marieberg collective house (Estocolmo, Suécia). No mesmo sentido, Despina Stratigakos tem vindo a refletir sobre o género e a modernidade nas cidades europeias - no livro mais recente, $A$ Women's Berlin (University of Minnesota Press, 2008), a autora explora a conceção da cidade construída por e para mulheres, um lugar imaginado mas parcialmente realizado anos antes da I Guerra Mundial.

\section{Literatura sobre arquitetura e género}

A maioria da abordagem feita ao tema "arquitetura e género" é produzida através de livros e coletâneas de artigos que evidenciam o ativismo político como origem, numa tendência sociopolítica de (re)conhecimento das profissões e das disciplinas relacionadas com o ambiente construído. A seleção e organização dos textos exploram temas criativamente elaborados, sem a lógica da sequência cronológica. As teses formuladas centram a perspetiva da mulher na arquitetura e concentram-se na exclusão do "feminino" tanto da prática/produção do espaço como na consideração das mulheres como habitantes da cidade e dos edifícios. Estas reflexões são produzidas através da recuperação de arquitetas esquecidas como protagonistas da profissão e da reavaliação da natureza de género da arquitetura, enquanto disciplina teorizada, praticada e ensinada.

A organização destas antologias exige, além de pesquisa, uma certa perspicácia, cumprindo um papel específico no avanço das ideias, especialmente quando relativas a um período dinâmico e caracterizado pela pluralidade e pela revisão de princípios dogmáticos. Construir uma trama própria, tentando alcançar um público mais amplo, permite expandir as fronteiras do debate e constituir um importante estímulo ao pensamento arquitetónico contemporâneo. A inexistência de um ponto de vista predominante nestas investigações colabora para a proliferação de novas teorias que pretendem explicar aspetos ainda desconhecidos, ou esquecidos, da disciplina. Em temas como significado, história, e sociedade, debate-se a cultura arquitetónica à luz de novos enquadramentos ideológicos e paradigmas teóricos, tais como a fenomenologia, a estética, a teoria linguística, o marxismo e o feminismo 
que, importados de outros ramos do conhecimento, modelam a teoria da arquitetura. A organização dos textos sob essas categorias e a participação de um mesmo autor em temas distintos garantem uma dinâmica fruição de ideias.

A sequência dos temas introduz um ritmo que é determinado pelo interesse do leitor. $\mathrm{Na}$ construção teórica que se vai estruturando pela sucessão de textos, o paradigma fenomenológico assume papel extremamente relevante uma vez que está na base das atitudes pós-modernas em relação ao sítio, ao lugar, à paisagem, à edificação, além de ressaltar o efeito que uma obra de arquitetura produz no observador. Partindo da contestação de antigos paradigmas - como o racionalismo e o antropomorfismo - propõe-se a sua substituição por outros capazes de desvendar a trama de uma nova (des)ordem estabelecida pelo prazer, pelo respeito às diferenças de género, classe e etnia, pela participação da mulher, e de minorias, na arquitetura.

\section{A cidade e a distinção entre homem/público e mulher/privado - A casa como metáfora do "feminino"}

The built form of the city is a complex representation of social, political, technological and economic forces; of ideals, ideologies and values over hundreds of years. Cities are cultural artefacts. Yet we live in cities where nearly $100 \%$ of the environment around us has been owned, legislated, designed and implemented by men (BROOKS, 2015, s.p.).

Diversos autores e autoras têm vindo a questionar o sentido hegemónico do espaço (público) urbano e a configuração do desenho das cidades, entendidas como uma acumulação de usos, fluxos, perceções, sistemas simbólicos e elementos de representação, cuja relevância se modifica ao longo do tempo e dos princípios socioeconómicos que produzem o espaço social. As cidades ocidentais promoveram, ao longo da história, uma estrutura urbana que criou separações rígidas baseadas em diferenças de classe, de etnia e de género, e o modo como elas conformaram as divisões espaciais nas esferas do lazer e do trabalho (ou seja, no traçado dos quarteirões, bairros, dos espaços laborais, nas áreas comerciais, etc.). Assim, as mulheres têm vindo a ocupar posições diferentes dos homens na cidade, como constata Elizabeth Wilson:

Woman is present in cities as temptress, as whore, as fallen woman, as lesbian, but also as virtuous womanhood in danger, as heroic womanhood who triumphs over temptation and tribulation [...] The city - as experience, environment, concept - is constructed by means of multiple contrasts: natural, unnatural; monolithic, fragmented; secret, public; pitiless, enveloping; rich, poor; sublime, beautiful. Behind all these lies the ultimate and major contrast: male, female; culture, nature; city, country (WILSON, 2000, p.150152).

A descoberta de experiências urbanas, arquitetónicas e artísticas contemporâneas, pretende desvendar a linguagem metafórica da cidade que poderá favorecer a realização de
(c) Urbana: Rev. Eletrônica Cent. Interdiscip. Estud. Cid. 
propostas libertadoras e um discurso capaz de produzir um espaço urbano mais plural. No primeiro capítulo do livro Políticas do Espaço: Arquitectura, Género e Controle Social de José Cortés (2008) - "Os espaços dóceis" - o autor analisa a capacidade da arquitetura de contribuir para a configuração de uma ordem social (e, portanto, de uma representação da autoridade), ao mesmo tempo que se distancia das ligações que detém com essa mesma ordem através de um discurso de (suposta) neutralidade. Da mesma forma que instituições como a família, a moral e o poder político procuram dominar e controlar o espaço, também a arquitetura pode atuar como instrumento repressivo sobre os corpos. A Place des Terreaux, no centro de Lyon (1994), é um exemplo do controlo exercido pelo desenho do espaço público: foram incorporadas nesta praça nove pequenas fontes no solo que, quando abertas, evitavam as usuais concentrações de árabes que ali ocorriam. Cortés recorre a Foucault quando nota que a domesticação da vida social, a normalização de espaços e de comportamentos, foram processos baseados em técnicas de controlo desenvolvidos desde o final do século XVIII; o ambiente construído envolvente pode não expressar em si a opressão ou a libertação mas é capaz de emoldurar a vida quotidiana e de condicionar as diferentes formas de prática social.

o valor que é dado aos espaços é determinado, em grande maioria, pela cultura dominante e através do "imperialismo cultural", o espaço deixa de se assumir como neutro (como, aliás, nunca o foi). Foi neste sentido que Cortés defendeu que a "cidade é masculina", recorrendo a uma série de elementos referenciais da arquitetura ocidental; por exemplo, explora os arranha-céus como manifestações fálicas e simbólicas do poder instituído. Neste ponto, a comparação com a forma fálica masculina deve ser entendida como uma imagem (vertical) arquitetónica emblemática do século $\mathrm{XX}$, que pretende representar a crescente globalização da economia e do poder corporativo, ambos do domínio masculino. Na segunda parte do livro - "Os corpos ausentes" - o autor incide sobre a forma como o mainstream da arquitetura manteve reprimida a sexualidade no espaço e o conservou esterilizado e neutro. No mundo ocidental, a subordinação cultural e social do feminino define-se, na produção do espaço público, mais por tudo aquilo que se nega do que por aquilo que se diz. São as atividades dos homens, as suashierarquias, prioridades e necessidades, que organizam a casa e planeiam a cidade em conformidade com os tempos e movimentos da masculinidade. A organização espacial tem necessariamente de refletir a representação das relações de género, revelando os privilégios e a autoridade masculinos como algo natural. Por conseguinte, é essencial uma desconstrução das visões da cidade - não é um espaço neutro e sem história - na qual está subjacente uma conceção atemporal e deslocalizada que pretende criar categorias universais de validação. Essa ideia implica uma falta de perceção das diferentes identidades e das diferenças entre elas, ao mesmo tempo que aposta na globalização e na totalidade, valores profundamente masculinos e típicos da racionalidade moderna. Cortés encerra o discurso sobre esta visão monolítica do espaço com o conceito de espaços queer que não correspondem a lugares mas a atitudes de apropriação fora da cidade contemporânea, numa permanente ideia de autoconstrução surgem, por isso, efémeros. A sua força libertadora reside somente na medida e no momento em que estão a ser criados: são os casos de East Village em Manhattan, o distrito Castro em

(c) Urbana: Rev. Eletrônica Cent. Interdiscip. Estud. Cid. $\quad$ Campinas (SP) $\quad$ v.7, n.2 [11] $\quad$ p.02-23 ISSN 1982-0569 
São Francisco ou o Chueca em Madrid. Deste ponto de análise parte-se para o vislumbre de cidades compostas por espaços de dúvida e de ambiguidade, por lugares de resistência que não desejam ser assimilados no processo de normalização.

\subsection{O sistema binário}

Num sentido mais abrangente, o conceito de dicotomia é essencial para a compreensão da estrutura simbólica patriarcal pois a classificação das pessoas em grupos de oposição este/oeste, futuro/passado, rico/pobre, novo/velho, masculino/feminino - cria um sistema social que justifica e suporta a supremacia masculina ocidental. Além de definir o espaço social, este sistema binário define a forma como conceptualizamos o espaço metafísico e o espaço físico. Numa sociedade que pretenda promover simultaneamente a máxima produtividade e o máximo consumo, as esferas público e privado têm distintos, mas complementares, papéis a desempenhar. Neste sentido, a arquitetura ajuda a reproduzir e reforçar esta divisão social por género, proporcionando uma imagem eficaz com valores próprios para cada uma.

A representação mais persuasiva de espaço/género é o paradigma das "esferas separadas", um sistema de oposições e hierarquias que consistiu no domínio do espaço público pelo homem (a cidade) e na subordinação do espaço privado feminino (a casa). Esta ideologia separa claramente a cidade da casa, o público do privado, a produção da reprodução, o homem da mulher. A crítica das teóricas e arquitetas feministas à construção dualista vai no sentido de mostrar quão redutor é este sistema em relação à realidade e à diversidade humana. A construção binária do género atribui certas características, domínios e atividades ao homem e os opostos à mulher - céu/terra, intelecto/sentimento, sagrado/profano, cultura/natureza, mente/corpo - e, consequentemente, se o homem assume o papel de construtor ativo do espaço, em teoria, relega-se a mulher ao papel passivo de ocupante. Como Weisman sugere "Architecture... is a record of deeds done by those who had the power to build" (apud ALEXANDER, 2011, p.1)

\section{2. "A Casa como o lugar da mulher e o paraíso do homem"3}

À exceção de algumas abordagens, como a feminista, o tratamento do espaço privado parte de esquemas funcionais que perpetuam um programa que esconde as principais questões sobre o projeto da habitação - a forma de pensar as áreas social, íntima e de serviço, mantêm os dogmas sobre a forma de habitar. Há também uma tendência em recorrer ao tema do abrigo primitivo (que, segundo estudos antropológicos, era frequentemente construído pelas mulheres) vinculado à crença de que nele se instituiu o espaço desde sempre habitável, humanizado, como essência da arquitetura. Como explica Dolores Hayden (1982),

3 "The home as a woman's place and a man's heaven" (WAJCMAN, 2001, p.194).

(c) Urbana: Rev. Eletrônica Cent. Interdiscip. Estud. Cid. Campinas (SP) v.7, n.2 [11]

p.02-23

ISSN 1982-0569 
Whether the private home is a free-standing house in Frank Lloyd Wright Broadacre City or a high tower flat in Le Corbusier's Radiant City, domestic work has been treated as a private, sex-stereotype activity, and most architects continue to design domestic work spaces for isolated female workers (WAJCMAN, 2001, p.194).

A idealização e romantização da casa fizeram com que se gerassem atitudes acríticas em relação aos sistemas morais e políticos em que esta está emaranhada. A maioria dos estudos sobre a casa, particularmente na conceção do espaço privado e a sua relação com o espaço urbano, focaliza-se pouco na problemática de género para a compreensão do habitar e da domesticidade.

Mark Wigley (1992) exalta a evidente cumplicidade entre a arquitetura e o exercício da autoridade patriarcal, que se define por uma intersecção entre a ordem espacial e o sistema de vigilância; por isso, as mulheres foram confinadas ao interior, numa sequência de espaços distantes do mundo exterior. A casa é literalmente entendida como um mecanismo para a domesticação da mulher e surge envolvida na produção da divisão de género; com a divisão hierárquica, a casa física é a possibilidade da ordem patriarcal: "The house is itself a way of looking" (WIGLEY, 1992, p.341). O autor expõe que, se por um lado, no $V$ Livro 'Desenho das casas privadas', L. Baptista Alberti (1404-1472) diferencia claramente os espaços da mulher e do homem, em termos de acesso, localização e níveis de conforto, por outro, Xenophon cria um espaço para a sexualidade - a própria casa. A invenção da privacidade pessoal é marcada por uma nova atitude em relação ao corpo que precisa de ser purificado e foi completada nos séculos posteriores pela redefinição dos espaços da casa numa complexa ordem de layers e pela subdivisão hierárquica da casa. Todavia, o ideal de privacidade individual aplicava-se apenas ao homem e a ideia de um espaço exclusivamente masculino implicava desde logo que a mulher só entrava com permissão. Na casa, o espaço intelectual encontrava-se restrito e mostra os limite da autoridade da mulher na casa: apesar da sua ação se resumir frequentemente ao lar, nem aqui ela controlava a totalidade do espaço.

A mulher ocupa o espaço feminino estereotipado - a casa - situando-se a si própria na sexualizada, emocional, personalizada, privatizada e instável esfera do lar, ao contrário do domínio público e impessoal. A noção de propriedade privada masculina é parte integrante da cultura ocidental, estende-se ao corpo feminino e está relacionada com uma identificação íntima da terra como objeto pois "[...] the house itself, the building and ownership of the house, belongs to the other side of the parable, the man's side" (INGRAHAM, 1996, p.36.

No século XIX, as tentativas de feministas americanas na transformação do espaço doméstico são interessantes na medida em que procuraram que a casa refletisse relações mais igualitárias entre os membros da família e que promovesse comportamentos mais democráticos. Propuseram cooperativas de trabalho doméstico, casas sem cozinha e com serviços comuns, como forma de coletivizar as tarefas domésticas. Apesar da revolução no consumo e da presença gradual da mulher no espaço público, a verdade é que esta ainda não está num espaço próprio, está em todos os lugares mas não pertence a nenhum, nem à casa nem à rua, nem ao privado nem ao público. O desejo de um espaço próprio significa a expressão física da consciência da 
individualidade pois historicamente, segundo diversos autores, a arquitetura responde a necessidades masculinas. Em The Split Wall: Domestic Voyerism (1992), Beatriz Colomina descreve a casa Moller (1928), desenhada pelo arquiteto Adolf Loos, através da teatralidade, do conforto e do controlo dos seus interiores - a zona de sentar elevada, comum a ambas, equipa o ocupante com um ponto de vantagem que domina o interior. A arquitetura de Loos não é simplesmente uma plataforma que acomoda o sujeito observador mas um mecanismo de contemplação que produz o sujeito e que precede e emoldura o seu ocupante e a vida doméstica do dia-a-dia. O único espaço restrito, mais calmo e privado é a biblioteca, do domínio intelectual masculino por excelência; a mulher localiza-se neste mundo entre o visível e o invisível.

\section{O corpo como metáfora arquitetónica}

Ao longo da história da arquitetura, a mulher tem sido substituída ou deslocada, não só no plano social geral mas de um modo mais específico através da intersecção do corpo com a arquitetura. As referências às proporções ideais dizem respeito ao corpo masculino, sobre as quais alguns autores arriscam ligá-la mais à ideia de falo do que de corpo - desta ideia decorre a excessiva ênfase dada ao carácter objetal da arquitetura. As fundações da arquitetura ocidental apoiam-se sobretudo nas regras e nos textos renascentistas; consequentemente, o "logocentrismo" e o "antropomorfismo" permaneceram subjacentes ao sistema arquitetónico que, desde Vitrúvio, é definido tanto pelo que inclui como pelo que exclui e reprime:

If sex condenses the notions of body and power that has permeated architectural criticism since the Renaissance revival of Classicism, an analysis of gender in modern architectural criticism reveals a social system that has historically functioned to contain, control, or exclude women (AGREST et al., 1996, p.11).

A relação entre os termos "sexualidade", "corpo" e "privacidade" é fundamentalmente histórica e a problemática do corpo em arquitetura está permanentemente ligada às questões (excluídas) do género e da sexualidade. Todavia, o corpo que serviu de medida ao discurso arquitetónico e que surgiu no centro das suas configurações e regras é masculino. Aliás, o discurso renascentista procedeu a uma operação simbólica que estabeleceu uma relação entre o homem e a natureza através de noções de harmonia natural e perfeição: o homem é apresentado como possuidor dos atributos, proporções e medidas ideais. Alberti explora um método mais elaborado de transformações metafóricas que produzem um sistema abstrato no discurso arquitetónico que incorporam as leis da natureza - a relação entre o corpo (do homem) e a arquitetura pode ser encontrado na obra Dez Livros de Arquitetura. Este processo de simbolização assume-se pela relação do corpo e das suas proporções com outros sistemas de proporções; o corpo como um sistema abstrato de formalização é incluído na arquitetura como forma, através das ordens, hierarquias e do sistema geral da organização formal - que permite 
que este discurso funcione ao nível do inconsciente. Nos trabalhos de Filarete ${ }^{4}$ e Francesco Di Giorgio a ambiguidade do género é uma questão eliminada pois é explicitamente referido que a figura humana é sinónimo da figura masculina:

"[...] a building is derived from men, that is, from his form, members, and measure [...] the exterior and interior parts and members are correct for the body of man [...] the building is truly a living man [...] the origins of the building and its origins in my opinion, how it is proportioned to the human body of man, now it needs to be nourished and governed and through lack it sickens and dies like man" (apud AGREST, 2000, p.362).

Di Giorgio promove analogias entre o corpo humano e a arquitetura à escala da cidade: "[...] the main square [piazza] should be placed in the middle and the center of that city or as close as possible, just as the navel is to man's body [...] his navel that human nature gets nutrition and perfection" (apud AGREST, 2000, p.365). O umbigo do homem torna-se o útero da mulher, capaz de dar vida à cidade. Refletindo sobre a feminização da arquitetura ocidental desde as suas fundações, parece inteligível esta necessidade e desejo do homem em se perpetuar, algo que a mulher faz naturalmente. Este é um dos pontos-chave do debate sobre o género e a arquitetura pois a forma como o homem procura incessantemente deixar uma marca no mundo que o imortalize sempre foi e é mais facilmente conseguida pela arquitetura do que por qualquer outra arte ou ciência. A eternização através de um edifício ou de uma cidade deixa uma marca visível e palpável no mundo, por vezes monumental, e pode influenciar o espaço e a vida públicos.

Sex. The word is layered with meaning and provocation. Embedded within it is the corporeal and the carnal, sensuality and desire, male and female, human reproduction. The inscription of the sexualized body is a central and recurrent theme in Western architecture, but that body is neither innocent nor androgynous. It is a reification of the male longing to appropriate an exclusively female privilege: maternity (AGREST et al., 1996, p.11).

Apesar da lógica do sistema arquitetónico reprimir a sexualidade, Filarete refere que o edifício é um "homem vivo" e que alguém tem de o "dar à luz". A figura do arquiteto torna-se feminizada, mulher e mãe, neste ato de procriação:

[...] who wishes to build needs a architect. He conceives it with him and then the architect carries it. When the architect has given birth he becomes the mother of the building. Before the architect gives birth, he should dream about his conception, think about it, and turn it over in his mind in many ways for seven to nine months [...] As the woman can do nothing without the man, so the architect is the mother to carry this conception (apud AGREST, 2000, p.363).

\footnotetext{
4 "[...] they were called by their Greek names, Doric, Ionic and Corinthian. The Doric (...) the one of major quality; the Corinthian is in the middle, the Ionic is the smallest for the reasons alleged by the architect Vitruvius in his book (...) As the building is derived from man, his measures, qualities, form and proportions, so the column also derived from the nude man and fluted from that well-dressed young women, as we said. Both are derived from the form of man. [...] Since man is the measure of all, the column should be measured and proportioned to his form". Filarete (Treatise on Architecture, 1461-63) (apud AGREST, 2000,
} p.370).

(c) Urbana: Rev. Eletrônica Cent. Interdiscip. Estud. Cid.

Campinas (SP)

v.7, n.2 [11]

p.02-23

ISSN 1982-0569 
A mulher é claramente substituída e excluída de todo o processo de pensar o edifício, é reprimida pela forma como se trata a arquitetura à imagem do homem, análoga do corpo do homem - o arquiteto já possui os atributos femininos necessários à conceção e à reprodução. Ironicamente, Diana Agrest afirma que

This conception without sex (sin) is the negation of sex as an essential part in the reproductive process [...] the architect can give birth to buildings or cities by usurping the female body, and just like Mary he can conceive without sex, only through spirit. Man is thus placed at the center of creation (AGREST, 2000, p.366).

Agrest defende então a reabilitação do corpo feminino na arquitetura, excluído desde Vitrúvio até ao Renascimento, numa postura que se prolongou até o Movimento Moderno. Se no projeto da arquitetura clássica (como corpo) a reflexão é o espelho de um sistema unitário e hermético, a cidade moderna lidou com a representação de um corpo fragmentado que não reflete o corpo do sujeito mas sim a sua perceção. Todavia, o corpo masculino continua a ser privilegiado em detrimento do feminino e apresenta-se como um protótipo arquitetónico - a mulher não tem lugar neste sistema. Em Ornamento e Crime, Adolf Loos afirma que a verticalidade do homem é uma manifestação da sua masculinidade, distinguindo-o do "Outro", o feminino:

[...] the first ornament that was born, the cross, was erotic in origin. The first work of art, the first artistic act which the first artist in order to rid himself of his surplus energy, ameares on the wall. A horizontal dash: the prone woman. A vertical dash: the man penetrating her. The man who created it felt the same urge as Beethoven, he was in the same heaven in which Beethoven created the Ninth Symphony (apud CONRADS, 1975, p.19).

Um dos temas que tem vindo a ser explorado pela arquitetura contemporânea é a sua relação com o corpo e com o evento/momento enquanto acontecimento que não se repete, dotado de uma singularidade espaço-temporal; uma questão que tem preocupado os arquitetos é exatamente o jogo entre a determinação e a indeterminação dos projetos e dos lugares deles resultantes. A desmaterialização do objeto arquitetónico ocorrido ao longo dos tempos parece acompanhar um progressivo distanciamento entre o corpo e a edificação. Se na antiguidade o edifício procurava uma analogia ao corpo em termos de proporção e simetria, posteriormente, o edifício passa a expressar sentimentos mais abstratos baseados nas sensações corporais. No início século $\mathrm{XX}$, a arquitetura e a cidade não estabelecem quase relação direta e metafórica com o corpo humano, mas sim com um animismo mais abrangente, no qual a edificação é vista como um organismo, que cresce, respira, se transforma e envelhece. Perante a irreversibilidade do tempo, o corpo pode transformar-se na peça-chave da arquitetura enquanto agente que articula o tempo e o espaço no momento, dentro de uma relação cada vez maior com a indeterminação; o corpo e o seu movimento passam efetivamente a construir e a moldar a arquitetura, interação que se faz e se refaz na relação com o habitante. Uma verdadeiraconsideração do corpo pode gerar uma arquitetura de carácter mais feminino, uma arquitetura da interioridade e de uma certa amabilidade? Aaron Betsky (1995, p.769) defende 
uma arquitetura da indeterminação, que se faz e se desfaz e que procura diferentes sensibilidades entre uma forma e outra; propõe então que essas novas abordagens sejam relacionadas ao que chama de corpo queer; as distinções entre o masculino e o feminino ganham outras ambiguidades e possibilidades de intercâmbio.

\section{Conclusão}

Os ensaios de um vasto leque de autores e autoras revelaram, ao longo do tempo, tanto o género associado ao espaço e à arquitetura (e vice-versa) como as vozes esquecidas das arquitetas, traduzindo a tentativa de descobrir a ligação da mulher ao ambiente construído através da sua própria perspetiva e do desejo de se instituírem como sujeitos no sistema arquitetónico. A partir da história do "pessoal" e do "íntimo", as mulheres podem estabelecer as estruturas da sua resistência e de permanência na construção do espaço de tal forma que acabem por traçar uma outra face da história "oficial". A combinação da voz "pública" com a voz "íntima" constrói a história que nunca foi contada, rompendo a cadeia ideológica erigida pela História (dos homens). Quanto mais pessoal e diversificada for essa narrativa, mais ela se torna verdadeira e abrangente na medida em que engloba as mais variadas experiências vividas pelas arquitetas e pelas mulheres que usufruem da cidade e da arquitetura. Segundo Alison Brooks,

Women in all sectors of society will increasingly change the way our cities operate, look and feel - not because of their gender, but because of the additional $50 \%$ of human creative intelligence that will be addressing the problems of the city (not to mention those less heroic topics, suburbs and rural environments) (BROOKS, 2015, s.p.).

O debate sobre o género, a mulher e a arquitetura, demonstraram uma aceitação generalizada das preocupações feministas mas, de forma mais perturbadora, marcaram quase um ponto final na visibilidade do feminismo na arquitetura no final do século $X X$ : as publicações são escassas e poucas escolas lecionam ainda sobre 'género e arquitetura'. Mary McLeod (2005) 5 nota que se, por um lado, as crescentes forças sociais e políticas parecem militar contra os estudos feministas, por outro, o seu próprio sucesso nas últimas quatro décadas parece ter ditado o seu declínio. Além fronteiras portuguesas, os nomes das arquitetas outrora esquecidas têm sido ressuscitados, as reputações dos heróis masculinos ficaram um tanto abaladas e os casos mais radicais de iniquidade sexual e discriminação na profissão foram denunciados grande parte do trabalho académico e da teoria feminista foi integrado noutros estudos e já fazem parte do mainstream da disciplina. O discurso sobre o género e as mulheres em arquitetura tem de progredir, tem de se (re)inventar e tem necessariamente de ser criativo.

Depois do debate estar lançado, falta incorporar o conceito de género no estudo da arquitetura e uma renovada consciencialização no "fazer e desenhar a cidade". Apesar de as

\footnotetext{
${ }^{5}$ Artigo traduzido por João Carvalhais em DIAS, Manuel Graça (org.). J.A : Ser Mulher : Being a Woman, Jornal dos Arquitectos, n0242 (Julho/ Agosto/Setembro 2011), pp.98-105.
} 
cidades estarem atualmente mais recetivas às questões da mulher e do lugar que ela ocupa, há outras questões de género que precisam de ser debatidas; neste sentido, Alison Brooks afirma que "We must encourage and educate the next generation of architects to use their skills and cultural perspective to impact society in more ways than buildings, and to be brave enough to have a public voice" (BROOKS, 2011, p.112).

\section{Referências}

AGREST, Diana (2000). Architecture from without: Body, Logic and Sex. In: RENDELL, Jane, PENNER, Barbara, BORDEN, Iain (orgs.) (2000). Gender Space Architecture: An interdisciplinary introduction, London: Routledge, pp. 358-370.

AGREST, Diana, CONWAY, Patricia, WEISMAN, Leslie Kanes (orgs.) (1996). The Sex of Architecture, New York: Harry N. Abrams.

ALEXANDER, Nancy (2011). The Ultimate within the Midst of Life: A Theory of Women's Sacred Space, 2011, Architecture, Culture, and Spirituality Symposium. [Consult. 20 Jan. 2012]. Disponível em WWW: <URL:http://www. acsforum.org/symposium2011/papers/alexander.pdf>. BETSKY, Aaron (1995). The Man Made World. In: BETSKY, Aaron (1995) Building Sex: Men, Women, Architecture, and the Construction of Sexuality, New York: William Morrow and Company.

BLOOMER, Jennifer (1991). Big Jugs. In: KROKER, Arthur, KROKER, Marilouise (orgs.) (1991). The Hysterical Male: New Feminist Theory, London: Macmillan.

BOYS, Jos (1996). Neutral gazes and knowable objects: Challenging the masculinist structures of architectural knowledge. In: RUEDI, Katerina, WIGGLESWORTH, Sarah, McCORQUODALE, Duncan (orgs.) (1996). Desiring Practices: Architecture, Gender and the Interdisciplinary, London: Black Dog Pub.

BROOKS, Alison (2011). On Societal and Challenges. In: KULLACK, Tanja (org.) (2011). Architecture: A Woman's Profession, Berlin: Jovis.

BROWN, Denise Scott- (2011). On Societal Changes and Challenges. In: KULLACK, Tanja, (org.) (2011). Architecture: A Woman's Profession, Berlin: Jovis.

BULLIVANT, Lucy (2015). How are women changing our cities?, The Guardian, 5 Março 2015. [Consult. 6 Mar. 2015]. Disponível em WW: <URL: http://www.theguardian.com/cities/2015/mar/05/how-women-changing-cities-urbanistasarchitecture-design $>$.

CEVEDIO, Mónica (2007). Arquitetura y género, espácio publico/espácio privado. Serie Mujeres, voces y propuestas,_Mora, no13.

COLOMINA, Beatriz (1992). The Split Wall: Domestic Voyeurism. In: COLOMINA, Beatriz (orgs.) (1992). Sexuality and Space, New Jersey: Princeton Papers on Architecture.

CONRAD, Ulrich (org.) (1975). Programmes and Manifestoes on $20^{\text {th }}$ - Century Architecture. 15a ed. The MIT Press. 
CORTÉS, José Miguel G. (2008). Políticas do Espaço : Arquitetura, Gênero e Controle Social, São Paulo: Editora Senac.

FIGUEIRA, Jorge (2011). Reescrever o Pós-Moderno : Sete entrevistas, Porto : Dafne Editora. HAYDEN, Dolores (1980). What would a non-sexist city be like? Speculations on Housing, Urban Design, and Human Work. Signs, Suplemento Women and the American City, vol.5, n03, pp.170187.

HOOKS, Bell (2000). Choosing the Margin as a Space of Radical Openness. In: RENDELL, Jane, PENNER, Barbara, BORDEN, Iain (orgs) (2000). Gender Space Architecture: An interdisciplinary introduction, London: Routledge.

INGRAHAM, Catherine (1996). Missing Objects. In: AGREST, Diana, CONWAY, Patricia, WEISMAN, Leslie Kanes (orgs.) (1996). The Sex of Architecture, New York: Harry N. Abrams. MCLEOD, Mary (2005). A Dream Deferred: Feminist Architecture History, Casabella, no 732. PETRESCU, Doina (org.) (2007). Altering Practices: Feminist Politics and Poetics of Space, London: Routledge.

RENDELL, Jane, PENNER, Barbara, BORDEN, Iain (orgs.) (2000). Gender Space Architecture: An interdisciplinary introduction, London: Routledge.

ROSE, Jaqueline (1985). Feminine Sexuality: Jacques Lacan and the École Freudienne, New York: W. W. Norton \& Company.

SOBRAL, Cláudia (2010). Roteiro Feminista quer mostrar que Lisboa também é das mulheres, Jornal Público, 28 Outubro 2010. [Consult. 1 Dez. 2011]. Disponível em WWW:<URL: http://www.publico.pt/Cultura/roteiro-feminista-quer-mostrar-que-lisboa-tambem-e-dasmulheres-1463217>.

VALE, Brenda (1996). Gender and an architecture of environmental responsibility. In: RUEDI, Katerina, WIGGLESWORTH, Sarah, McCORQUODALE, Duncan (orgs.) (1996). Desiring Practices: Architecture, Gender and the Interdisciplinary, London: Black Dog Pub.

WAJCMAN, Judy (2001). The Built Environment: Women's Place, Gendered Place. In: WYER, Mary et al. (orgs.) (2001). Women, Science and Technology: A Reader in Feminist Science Studies, New York: Routledge.

WEISMAN, Leslie Kanes (1994). Discrimination by Design: A Feminist critique of the man-made environment, Urbana: Illini Books. ISBN 0-252-06399-6

WEISMAN, Leslie Kanes (2000). Prologue. In: RENDELL, Jane, PENNER, Barbara, BORDEN, Iain (orgs.) (2000). Gender Space Architecture: An interdisciplinary introduction, London: Routledge. WIGLEY, Mark (1992). Untitled: The Housing of Gender. In: COLOMINA, Beatriz (orgs.) (1992). Sexuality and Space, New Jersey: Princeton Papers on Architecture, pp. 326-389.

WILSON, Elizabeth (2000). Into the Labyrinth. In: RENDELL, Jane, PENNER, Barbara, BORDEN, Iain (orgs.) (2000). Gender Space Architecture: An interdisciplinary introduction, London: Routledge. WHITE, Deborah (2001). Masculine Constructions: Gender in twentieth-century architectural discourse: 'Gods', 'Gospels' and 'tall tales' in Architecture. Adelaide: [s.n.], Outubro 2001. Tese de Doutorado apresentada à University of Adelaide, School of Architecture, Landscape Architecture and Urban Design.

(c) Urbana: Rev. Eletrônica Cent. Interdiscip. Estud. Cid. $\quad$ Campinas (SP) $\quad$ v.7, n.2 [11] $\quad$ p.02-23 ISSN 1982-0569 
TORRES, Susana (2000). Claiming the Public Space: The Mothers of Plaza de Mayo. In: RENDELL, Jane, PENNER, Barbara, BORDEN, Iain (orgs.) (2000). Gender Space Architecture: An interdisciplinary introduction, London: Routledge. 